\title{
IMPACTOS DO CRESCIMENTO DO CONSUMO DE CAFÉS ESPECIAIS NA COMPETITIVIDADE INTER-REGIONAL DA ATIVIDADE CAFEEIRA
}

\author{
Mônica de Moura Pires ${ }^{1}$ \& Antônio Carvalho Campos $^{2}$ \\ Marcelo José Braga ${ }^{3}$ \& José Luís dos Santos Rufino ${ }^{4}$
}

Resumo - Este trabalho tem como objetivo avaliar os impactos da expansão do consumo de cafés especiais no crescimento da competitividade inter-regional da atividade cafeeira e na distribuição funcional da renda. Os fluxos de bens e serviços contidos na Matriz de Contabilidade Social - MCS constituíram a base de dados para a construção do modelo aplicado de equilíbrio geral - MCEG. Um aumento de $1 \%$ no consumo mundial de café foi distribuído de forma diferenciada por região produtora: $30 \%$ para o Oeste Baiano, $25 \%$ para o Cerrado Mineiro, 25\% para o Sul de Minas e 20\% para a Zona da Mata Mineira. Os resultados indicam que a expansão da demanda internacional revela efeito positivo sobre as regiões produtoras com maior potencial de crescimento para a oferta de cafés especiais. O choque na demanda de café não foi acompanhado por choques de demanda em outros setores, o que provocou elevação nos preços dos fatores e, conseqüentemente, diminuição nos níveis do emprego dos fatores produtivos. A reestruturação espacial da atividade produtiva, para atender à demanda de nichos de mercados, apresenta-se, assim, potencialmente promissora para o produtor como forma de manutenção da competitividade do café brasileiro no mercado internacional.

\footnotetext{
${ }^{1}$ Professora Adjunta da Universidade Estadual de Santa Cruz, Departamento de Ciências Econômicas - UESC/DCEC - (e-mail: mpires@uesc.br).

${ }_{2}$ Professor Titular da Universidade Federal de Viçosa, Departamento de Economia Rural - UFV/DER.

${ }^{3}$ Professor Adjunto da Universidade Federal de Viçosa, Departamento de Economia Rural - UFV/DER.

${ }^{4}$ Pesquisador da EMBRAPA - Brasília-DF.
} 
Palavras-chave: café de qualidade, competitividade inter-regional, mercado internacional.

\section{Introdução}

Durante muito tempo, grande parte dos cafeicultores brasileiros esqueceu-se de que havia um mercado internacional competitivo para ser disputado. Isso porque a política de armazenagem do extinto Instituto Brasileiro do Café (IBC), órgão que normatizava o mercado de café, retinha estoques ilimitados de qualquer tipo de café que fosse produzido. Além disso, o mercado doméstico, importante consumidor de café, servia de conveniente receptáculo para a produção de cafés de qualidade não-exportável. A conseqüência mais nítida foi a perda de competitividade do café brasileiro no mercado internacional, principalmente quando esse mercado passou a premiar a qualidade do produto. Nos últimos anos, o consumidor do mercado nacional também passou a ser mais exigente com o aspecto da qualidade, o que fez com que tivesse acesso a um café classificado no mercado como bebida fina para consumo.

O descaso com a qualidade do café brasileiro, no passado recente, abriu espaço para que outros países se especializassem na produção de determinados tipos de café. A Colômbia e o México, por exemplo, desenvolveram a produção de cafés do tipo arábica suave. Em nível internacional, a Colômbia é o primeiro produtor desse tipo de café no mundo (ANUÁRIO BRASILEIRO DO CAFÉ, 2001). Para esse país, diferentemente do Brasil, o mais importante era posicionar o seu café no mundo, com as características de um produto com alto padrão de qualidade. A finalidade era maximizar a receita recebida em dólares e não o volume exportado do produto.

No passado recente, tem-se percebido um crescente aumento da demanda por cafés especiais, tanto nos mercados europeu como no americano. Nos Estados Unidos, esse segmento do consumo já corresponde a, aproximadamente, $37 \%$ do volume total das vendas (GAZETA MERCANTIL, 1997). Deve-se ressaltar, também, o crescimento da demanda do café expresso, dos aromatizados e dos cafés 
de origem, bem como dos cafés de torrefação e moagem diferenciados. Essas novas exigências do mercado consumidor fazem com que a qualidade seja um fator cada vez mais importante, pois, no caso dos cafés especiais, o padrão básico de concorrência é a qualidade e, raramente, o preço. Nesse processo, a diferenciação do produto tornase instrumento fundamental para consolidar e criar novos mercados.

Ao longo dos anos, modificações foram introduzidas no setor por meio de variedades mais produtivas de café, do maior uso de fertilizantes e defensivos agrícolas e do emprego mais intensivo da mecanização agrícola, principalmente nas novas regiões produtoras do país, como nas regiões do Cerrado Mineiro e do Oeste Baiano. Deve-se ressaltar, porém, que a adoção de novas técnicas por parte do produtor depende da sua expectativa de lucro, dada pela relação custo/ benefício. Tal relação, portanto, determinará a intensificação desse processo de adoção de novas tecnologias. Em decorrência das mudanças nas preferências nos mercados externo e interno de café, os produtores têm buscado novas estratégias para o desenvolvimento da atividade, tornando-se mais atentos às exigências do mercado consumidor, principalmente no que se refere à questão da qualidade do produto. As novas estratégias têm sido baseadas nos resultados de pesquisas que se destinam, fundamentalmente, à melhoria da qualidade e da produtividade do café. Para isso, o governo federal criou o Programa Cafés do Brasil para certificação da origem e da qualidade do café, como forma de reconhecimento das especificidades regionais.

As regiões do Cerrado, Sul de Minas e Mogiana Paulista têm merecido destaque, visto que se especializaram na produção de um produto de alta qualidade. Essas regiões estão entre as melhores do mundo em qualidade do produto, o que pode ser creditado ao clima favorável, aliado às técnicas de cultivo e de administração modernas, que favorecem a colheita de um produto diferenciado das outras regiões do país. As características das principais regiões produtoras de café arábica em Minas Gerais, São Paulo, Paraná e Bahia são bastante distintas. Torna-se, portanto, necessário identificar o potencial competitivo de cada uma delas, para que medidas de política possam ser direcionadas, com vistas a otimizar os seus efeitos à jusante e à 
montante, promovendo, assim, o impacto almejado tanto na atividade como na economia regional.

Este estudo espera contribuir para essa reorientação da produção cafeeira no Brasil, indicando as potencialidades regionais associadas com as mudanças na demanda dos consumidores, mostrando os efeitos decorrentes dessas medidas na economia e nos diversos segmentos da cadeia produtiva do café.

\subsection{Objetivos}

O objetivo geral deste estudo é avaliar os impactos da expansão do consumo de cafés especiais no crescimento da competitividade inter-regional da atividade cafeeira e na redistribuição funcional dos rendimentos.

Especificamente, pretende-se:

a) avaliar as competitividades dos diferentes sistemas regionais de produção face às segmentações do mercado cafeeiro; e

b) determinar os efeitos diretos e indiretos de mudanças nas preferências dos consumidores sobre as remunerações dos recursos produtivos.

\section{Metodologia}

\subsection{Modelo teórico}

Os modelos multissetoriais vêm sendo aplicados às questões que envolvem estratégias de crescimento e ajuste estrutural. No início dos anos 70, surgiu uma nova categoria de modelos multissetoriais capaz de simular o funcionamento de uma economia de mercado. Esses modelos, denominados modelos computáveis de equilíbrio geral (MCEG), são os sucessores dos modelos tradicionais de insumo-produto. Tais modelos caracterizam-se por permitir a substituição de fatores e produtos na oferta e na demanda, além de introduzirem um sistema de preços de mercado e uma 
completa especialização dos fluxos de renda e de produto (NAJBERG et al., 1995).

Os modelos multissetoriais são os instrumentos mais utilizados para mensurar os impactos de medidas de política econômica ou choques exógenos. Esses modelos procuram representar o sistema econômico de forma mais completa e realista, pois não se restringem à quantificação de fatos econômicos. Muitas vezes, eles esclarecem algumas relações pouco evidentes em uma análise parcial convencional. De modo geral, podem ser classificados em três grupos: a) modelos macroeconômicos, destinados à análise do equilíbrio entre os agregados da economia, por meio da utilização dos multiplicadores de impacto; b) modelos de insumo-produto, elaborados a partir da matriz de Leontief, que focalizam, basicamente, a composição setorial da produção e da demanda e, dessa forma, o consumo intermediário; e c) os MCEG, que são uma versão moderna do modelo econômico walrasiano de economia competitiva, que incorpora os efeitos de variáveis micro e macroeconômicas e os seus mecanismos de ajuste (CASTILHO, 1994).

O MCEG a ser desenvolvido neste trabalho baseia-se nos conceitos econômicos da teoria da localização espacial e na teoria do comércio intra-regional (AZONNI, 1982; CAPOZZA e ORDER, 1978; NORTON, 1979; PORTER, 1993; TOMEK; ROBINSON, 1991; WEIGHT, 1982). Para que tais conceitos possam ser aplicados, tornase necessário o conhecimento do comportamento do mercado e de suas especificidades, no que se refere às estruturas de custos e ao tipo de produto gerado em cada região, ou seja, aspectos relacionados com os diversos sistemas de produção da atividade estudada. É importante salientar que todos os elementos descritos são fundamentais no processo de diferenciação do produto e, conseqüentemente, na qualidade e no preço. Aliadas a esses fatores, medidas de política econômicas devem ser adotadas para corrigir imperfeições porventura existentes, para que o produtor promova uma alocação eficiente de seus fatores de produção. 


\subsection{Modelo analítico}

A Matriz de Contabilidade Social - MCS foi construída a partir da matriz de insumo produto e das contas nacionais elaboradas pelo Instituto Brasileiro de Geografia e Estatística - IBGE (PIRES, 2001). Como este trabalho objetiva avaliar os impactos de mudanças na competitividade da atividade cafeeira em diferentes locais de produção e na distribuição funcional da renda, as atividades econômicas foram agregadas em 26 setores, sendo: café (dividido em sete setores), outros da agropecuária, outros manufaturados, energia, máquinas e tratores, mecânica e elétrica, indústria química, álcool de cana e cereais, fertilizantes, fibras têxteis, produtos do café, arroz beneficiado, farinha de trigo, carne bovina, aves abatidas, laticínios, açúcar, óleos vegetais, serviços, serviços financeiros e margem de comércio e transporte e administração pública. A subdivisão da atividade cafeeira em sete diferentes atividades tem a finalidade de destacar as particularidades regionais e os tipos de café produzidos no Brasil, o que permite captar também as diferenças tecnológicas existentes entre as principais regiões produtoras de café arábica no Brasil. A transformação dos dados básicos das tabelas de insumo-produto em coeficientes técnicos diretos foi efetuada sob a hipótese de tecnologia do setor, conforme Ramos (1997), citado por Braga (1999). Os produtores minimizam seus custos no processo de escolha dos insumos a serem utilizados na produção. As restrições são determinadas pela tecnologia de produção. Supondo que cada região produza um produto de qualidade diferenciada e, portanto, apresente tecnologias de produção diferentes, tem-se uma "árvore de produção" para cada região.

A função de produção utilizada é aninhada (nested), tendo três níveis de aninhamento (nesting) e quatro elasticidades de substituição. Essa formulação possibilita a separação dos insumos utilizados na produção, restringindo, assim, o número de parâmetros no modelo. Os fatores de produção, capital e trabalho, são combinados em uma cesta compósita. Dessa forma, os produtores, no curto prazo, não podem modificar a combinação capital/trabalho, razão por que a elasticidade de substituição nesse nível é zero. Terra e fertilizante são 
combinados em proporções variáveis para formar o insumo terra melhorada. Pressupondo que os produtores procuram minimizar seus custos, o problema é a determinação da combinação ótima de terra melhorada e trabalho. Os outros insumos entram em proporções fixas.

As tecnologias para produtos não-agrícolas definem o valor adicionado por meio da combinação de capital e mão-de-obra em proporções fixas. Os insumos intermediários são empregados em proporções fixas para o produto, exceto no caso da agroindústria de alimentos. Nesse caso, os insumos são combinados entre si, dentro de um compósito de alimentos em proporção variável, de acordo com as elasticidades de substituição especificadas.

Os níveis de consumo das famílias são baseados na renda e nos preços, distribuídos entre consumo presente (serviços, energia, alimentos, transporte e outros manufaturados) e consumo futuro (poupança). A estrutura de demanda doméstica baseia-se em funções de preferências em um sistema de dispêndio com elasticidade de substituição constante - CES.

Os modelos de equilíbrio geral não são testados em qualquer nível estatístico de significância. Os parâmetros utilizados no modelo são calibrados e não há um teste estatístico para a especificação do modelo. Constituem, assim, modelos determinísticos, nos quais os consumidores maximizam a utilidade e as firmas lucros, obedecendo às condições de equilíbrio, ou seja, demanda igual à oferta.

O fechamento do modelo apresentado é neoclássico, pois se considera que o investimento total seja determinado pelo nível de poupança. No que se refere ao setor externo e ao governo, o fechamento empregado é o mesmo adotado por Ferreira Filho (1995) e Braga (1999). Assim, quanto ao setor externo, o fechamento foi feito pelo racionamento de importações, que deve ser igual à disponibilidade de divisas. A taxa de câmbio nominal é o numerário e o fluxo de capitais externos é exógeno. O índice de preços ao consumidor foi calculado a partir dos dados de consumo de todos os bens, ponderados pela sua participação no consumo total.

O modelo incorpora a hipótese de rigidez salarial, ou seja, o trabalho fica sujeito à restrição de salário mínimo, abaixo do qual há 
excesso de oferta de mão-de-obra. Dessa forma, o salário real não varia em relação ao índice de preços durante as simulações, o que justifica a condição de desemprego. Com relação ao capital, a flexibilidade deste é limitada no que se refere à sua realocação, restringindo sua mobilidade. Assim, obtêm-se soluções de equilíbrio em que pode não haver plena utilização da capacidade instalada.

\subsection{Operacionalização do modelo}

Neste modelo têm-se as mercadorias e serviços, os consumidores (famílias, governo e exterior), os produtores e as restrições auxiliares e as funções de produção e de utilidade. Considera-se que as funções apresentam retornos constantes de escala. Todos os agentes econômicos tomam o preço como dado, ou seja, ele é determinado pelo mercado, a moeda é considerada neutra e apenas os preços relativos são relevantes. O MCEG básico é descrito por um sistema de equações simultâneas não-lineares que expressam as decisões dos agentes, sendo o mecanismo de preços fundamental na alocação dos recursos. As equações são apresentadas sob a forma de funções CES.

Os dados básicos das tabelas de insumo-produto foram transformados em matrizes de coeficientes técnicos, adotando-se a hipótese de tecnologia do setor, em que a tecnologia para produção dos produtos é aquela da atividade que o produz. Adotou-se o sistema produto por produto, obtendo-se uma matriz de insumo-produto com dimensão 80 x 80 e um nível de agregação definido de acordo com o estudo. Os elementos dessa matriz foram expressos em preços básicos aproximados.

Assim, em consonância com o modelo econômico adotado, realizou-se a agregação dos setores e das atividades da matriz de insumo-produto brasileira, elaborada pelo Instituto Brasileiro de Geografia e Estatística (IBGE) em 1995. Posteriormente, os dados brutos coletados foram transformados de acordo com a estrutura teórica da análise de insumo-produto, o que tornou possível a construção de matrizes de coeficientes técnicos. Em seguida, construiu-se a MCS, com dimensão $32 \times 32$ e quatro tipos de contas: conta de atividades (26 
atividades agregadas); conta dos fatores de produção (trabalho e capital); conta das instituições domésticas (famílias, governo e FBCF); e conta do resto do mundo.

Nos critérios para desagregar a atividade café foram considerados a localização geográfica da cultura e o diferencial tecnológico, ou seja, as sete atividades de café estão associadas a diferentes tecnologias de produção e à representatividade da produção de café das regiões estudadas na produção nacional.

O Café 1 (Barreiras) e o Café 6 (Cerrado) representam a nova fronteira tecnológica de produção de café e responderam, respectivamente, em 1995 , por $0,02 \%$ e $9,98 \%$ da produção nacional (ANUÁRIO ESTATÍSTICO DO BRASIL, 1996). Os Cafés 2, 3, 4, 5 e "Outros Cafés" estão relacionados com a atividade nas regiões do Paraná, São Paulo, Zona da Mata de Minas Gerais, Sul de Minas e Outras regiões brasileiras e representam, respectivamente, 1,08\%, $11,03 \%, 11,23 \%, 17,69 \%$ e 48,98\% da produção nacional.

A MCS representa, portanto, a situação real da economia brasileira no ano de 1995 e constitui a principal fonte de dados do modelo. A partir das informações contidas na MCS procedeu-se a simulação de referência, que consiste na calibração do modelo de modo que o mesmo reproduza o equilíbrio inicial dado pela MCS. De posse desse cenário básico, estabeleceram-se as simulações subseqüentes. Para cada simulação, o modelo foi resolvido para as variáveis endógenas, tomando os valores dados para as variáveis exógenas e demais parâmetros. Dessa forma, os fluxos foram alterados e, consequientemente, refletiram os efeitos dos choques sobre as variáveis relacionadas com o objeto de estudo.

\section{5 Área de estudo e fonte dos dados}

Este estudo abrangeu as principais regiões produtoras de café arábica no Brasil, que são Minas Gerais, São Paulo, Paraná e Bahia, escolhidas para o estudo devido à importância que possuem na atividade cafeeira, tanto no cenário nacional como no internacional. Neste estudo utilizaram-se as tabelas de insumo-produto elaboradas 
pelo IBGE, no ano de 1995. Dados complementares foram obtidos do Boletim do Banco Central, das contas nacionais, dos censos agropecuários, da Empresa Brasileira de Pesquisa Agropecuária (EMBRAPA), da Empresa de Pesquisa Agropecuária de Minas Gerais (EPAMIG), da AGRIANUAL, da Empresa de Assistência Técnica e Extensão Rural (EMATER) e de cooperativas de produtores de café. O modelo incorpora o nível médio de desemprego de 4,6\% na economia (ANUÁRIO ESTATÍSTICO DO BRASIL, 1996). Neste trabalho, utilizou-se o algoritmo Mathematical Programming Systems for General Equilibrium (MPSGE), que, a partir dos dados compilados na MCS, gera novas soluções de equilíbrio.

\section{Resultados e Discussão}

No desenvolvimento deste estudo parte-se da premissa que há um crescimento mundial no consumo de cafés especiais. Tal crescimento permite elaborar um cenário analítico em que modificações nos padrões de consumo (demandas interna e externa) resultem em mudanças nos sistemas de produção da atividade cafeeira, necessárias ao crescimento da competitividade internacional do produto. $\mathrm{O}$ cenário proposto caracteriza uma alteração a ser efetuada na condição do equilíbrio inicial, de forma a representar a nova situação que se espera acontecer no mercado cafeeiro, principalmente quando se consideram as tendências da última década.

Partindo-se de um aumento global de $1 \%$ no consumo de café, fundamentado na taxa média de crescimento do consumo mundial de 1,3\% a.a. nos anos noventa, procura-se evidenciar uma tendência do mercado que sinaliza um maior potencial de crescimento para a demanda de cafés classificados como de melhor qualidade, bebidas mole e dura. Para tal, distribui-se, de forma diferenciada, esse aumento no consumo entre as diversas regiões produtoras de café. As regiões que apresentam maior potencial de resposta às alterações no consumo final foram as mais beneficiadas na distribuição das cotas resultantes do aumento de $1 \%$ na demanda final. Nessa perspectiva, o choque inicial (crescimento de $1 \%$ na demanda) foi distribuído da seguinte 
forma: $30 \%$ para o Oeste Baiano, 25\% para o Cerrado Mineiro, 25\% para o Sul de Minas e 20\% para a Zona da Mata Mineira. Incluiu-se o café produzido na região Zona da Mata, haja vista o mercado cativo que essa região desfruta nos países árabes. Admite-se, também, que a expansão do consumo de café não implique respostas diretas da produção nas demais regiões produtoras. No entanto, o modelo pode captar, nessas regiões, os efeitos secundários resultantes da implementação do choque de demanda em outras regiões. Como neste cenário não se implementam alterações diretas na oferta de café, há, inicialmente, um efeito de elevação no preço do café, o que pode provocar uma mudança endógena na quantidade ofertada. No caso da substituibilidade entre os tipos de café, adotam-se níveis diferenciados para as elasticidades de substituição. Portanto, considera-se que não há substituição entre os cafés de melhor qualidade e os demais cafés.

Os resultados evidenciam que a expansão da demanda de café tem efeito positivo sobre a atividade cafeeira nas regiões que apresentam maior potencial de crescimento, como em Barreiras $(544,4 \%)$ na Bahia e Zona da Mata (2,72\%), Cerrados (1,32\%) em Minas Gerais (Tabela 1). A região do Sul de Minas Gerais, apesar de produzir café de alta qualidade, não apresentou resposta proporcional àquelas das regiões de Barreiras, Mata Mineira e dos Cerrados. O crescimento do nível de atividade de Barreiras em 544,4\%, em relação ao equilíbrio inicial, pode estar relacionado com uma forte realocação das atividades agrícolas nessa região e, ou, com a mobilidade dos fatores de produção de outras regiões produtoras de café. Ressalta-se, porém, que a produção do Oeste Baiano já superava as 200 mil sacas, em 2000, o que mostra o expressivo crescimento da atividade cafeeira nessa região.

Os resultados indicam também que o aumento no nível de atividade de uma região implica reduções no nível de atividade de outras regiões. Desse modo, o choque de demanda provoca um deslocamento da atividade cafeeira para as regiões mais intensivas em capital e, ou, que possuam mercados cativos, como é o caso da Zona da Mata de Minas. Em resposta a esse crescimento da demanda, os preços aumentam em, aproximadamente, $0,03 \%$, ceteris paribus. Em face desses novos níveis de preço, a indústria processadora de 
café reduz sua produção em $0,14 \%$. Como a expansão da demanda não foi acompanhada pelo crescimento da oferta, houve um efeito negativo sobre as exportações de café, mas em níveis relativamente pequenos, o que implica em estabilidade na receita de exportação (Tabela 1).

Tabela 1 - Efeitos do crescimento da demanda final de cafés especiais sobre os níveis de atividades e preços relacionados com os diversos sistemas da atividade cafeeira

Atividade

Nível de Atividade*
Nível de Preços*

\begin{tabular}{lrc}
\hline Café 1 & 544,40 & 0,02 \\
Café 2 & $-0,63$ & 0,03 \\
Café 3 & $-0,77$ & 0,03 \\
Café 4 & 2,72 & 0,02 \\
Café 5 & 0,73 & 0,03 \\
Café 6 & 1,32 & 0,02 \\
Outros cafés & $-0,32$ & 0,03 \\
Café processado & $-0,14$ & 0,01 \\
Exportação café & $-0,01$ & $-0,02$ \\
\hline
\end{tabular}

Fonte: Resultados da pesquisa.

* Variação percentual em relação ao Equilíbrio Inicial.

Os comportamentos dos níveis das atividades sugerem que o direcionamento dos incrementos no consumo de café para as regiões selecionadas promove uma realocação da produção nacional em condições de maior eficiência, o que melhora a competitividade do café brasileiro. O aumento da oferta de café na região Oeste da Bahia deverá influenciar o desempenho das outras regiões produtoras no Brasil, promovendo mudanças importantes tanto no mercado cafeeiro como em outras atividades agrícolas.

Considerando o cenário estabelecido, apenas os cafezais de Barreiras, da Zona da Mata, do Sul de Minas e do Cerrado Mineiro 
apresentaram respostas diretas ao choque de demanda (Tabela 1). Nos cafezais do Paraná, São Paulo e de outros Estados, não houve, na simulação, respostas positivas diretas em seus níveis de atividade, ou seja, as ofertas dessas regiões diminuíram quando se simulou uma pressão do consumidor por cafés de melhor qualidade. O realismo dessa simulação pode ser explicado por dois fatores: primeiro, as tradicionais regiões produtoras de café no Paraná e em São Paulo têm perdido competitividade face à ocorrência de fatores climáticos adversos, como geadas; e, segundo, muitos dos produtores paulistas que estão retornando à atividade têm direcionado sua produção para o café robusta, que constitui a principal matéria-prima para a produção do café solúvel.

Os argumentos de crescimento da produção da região de Barreiras devem-se à expectativa da Secretaria de Agricultura do Estado da Bahia de atingir 1,3 milhão de sacas em 2003. Considerando a disponibilidade regional de terras agricultáveis, haveria, assim possibilidade de ampliar, efetivamente, a produção de café em Barreiras e, assim, constituir-se na nova fronteira da cafeicultura brasileira, atraindo produtores de outras regiões, em razão do baixo preço relativo das terras e dos incentivos oferecidos pelo governo estadual. Caso se confirmem as expectativas dos crescentes aumentos na demanda de café de melhor qualidade, as regiões que melhor se adaptarem a essas novas tecnologias de produção e realizarem um marketing mais agressivo do seu produto poderão conquistar maiores parcelas de mercado e, conseqüentemente, desfrutarem de maiores taxas de crescimento em seus níveis de atividades.

Tendo em vista os ajustes da produção nos níveis propostos neste cenário, a participação da região de Barreiras passaria de 0,02\% para $0,10 \%$ na produção nacional. Por outro lado, as alterações na demanda provocariam efeitos contrários em São Paulo e nas regiões produtoras de "Outros Cafés" no Brasil, onde as produções diminuiriam em 13 e 27 mil sacas, respectivamente. Observa-se, porém, que Minas Gerais aumentaria a produção em todas as suas regiões produtoras em, aproximadamente, 88 mil sacas (Tabela 2). 


\section{Tabela 2 - Produção de café no Brasil, por regiões, 1995 (em sacas de $60 \mathrm{~kg}$ )}

\begin{tabular}{lrccc}
\hline Atividades & $\begin{array}{c}\text { Produção } \\
\mathbf{1 9 9 5 / 1 9 9 6}\end{array}$ & $\begin{array}{c}\text { Participação por } \\
\text { região (\%) }\end{array}$ & $\begin{array}{c}\text { Produção } \\
\text { estimada* }\end{array}$ & $\begin{array}{c}\text { Participação por } \\
\text { região (\%) }\end{array}$ \\
\hline Café 1 & $2.500,00$ & 0,02 & $16.109,96$ & 0,10 \\
Café 2 & $167.358,33$ & 1,08 & $166.309,44$ & 1,07 \\
Café 3 & $1.710 .000,00$ & 11,03 & $1.696 .850,04$ & 10,88 \\
Café 4 & $1.741 .366,67$ & 11,23 & $1.788 .654,15$ & 11,47 \\
Café 5 & $2.742 .000,00$ & 17,69 & $2.761 .959,23$ & 17,72 \\
Café 6 & $1.546 .741,67$ & 9,98 & $1.567 .191,62$ & 10,05 \\
Outros cafés & $7.592 .275,00$ & 48,98 & $7.565 .661,43$ & 48,53 \\
Brasil & $\mathbf{1 5 . 5 0 2 . 2 4 1 , 6 7}$ & $\mathbf{1 0 0 , 0 0}$ & $\mathbf{1 5 . 5 8 9 . 3 4 9 , 4 5}$ & $\mathbf{1 0 0 , 0 0}$ \\
\hline
\end{tabular}

Fonte: Resultados da pesquisa.

Esses ajustes indicam uma maior racionalidade na utilização dos recursos produtivos, que é obtida pela redistribuição da produção de café, privilegiando as regiões com maior potencial de resposta ao novo tipo de demanda que está mais exigente nos requisitos de qualidade do produto.

Observa-se, portanto, que o crescimento da demanda final de cafés especiais implicou aumento da produção nas regiões de Barreiras, Zona da Mata, Sul de Minas e Cerrado Mineiro, tornando-as mais competitivas em comparação à situação de equilíbrio inicial. Assim, a segmentação do mercado cafeeiro melhoraria a competitividade dessas regiões, propiciando uma redistribuição inter-regional da renda.

Em relação aos índices agregados (Tabela 3), observa-se a redução da utilização do capital agrícola $(0,007 \%)$, a queda no nível de emprego rural $(0,93 \%)$ e o aumento do emprego urbano $(0,07 \%)$. Desse modo, os incrementos das demandas interna e externa exerceram pouca pressão nos preços dos fatores de produção. Porém, o modelo incorpora as restrições relativas às indexações dos salários e da taxa de retorno ao 
capital ao índice de preços ao consumidor. Assim, para que as soluções de equilíbrio sejam alcançadas, essas restrições não permitem taxas de crescimento negativas para o salário real e para a rentabilidade do capital, justificando-se a condição de desemprego e, ou, de subutilização da capacidade instalada na nova situação de equilíbrio.

\section{Tabela 3 - Efeitos do crescimento do consumo de café sobre níveis de emprego, renda e índice de preços ao consumidor}

\begin{tabular}{lrc} 
Atividade & Equilíbrio inicial (EI) & Variação \% em relação ao EI \\
\hline Renda $\left(\mathbf{1 0}^{\mathbf{6}} \mathbf{R} \$\right)$ & $390.215,00$ & $-0,001$ \\
Famílias & $108.435,00$ & $-0,002$ \\
Governo & $24.365,10$ & $-0,003$ \\
Exterior & & \\
Capital & 0,565 & $-0,007$ \\
Rural & 0,714 & 0,001 \\
Urbano & & $-0,929$ \\
Mão-de-obra & 0,083 & \\
Rural & & 0,001 \\
Urbana 0,047 0,073 & 0,758 & \\
Índice de preços ao consumidor & & \\
\end{tabular}

Fonte: Resultados da pesquisa.

O índice de preços ao consumidor aumentou apenas 0,001\% e as rendas das famílias, do governo e do exterior foram afetadas negativamente, mostrando decréscimos de 0,001\%, 0,002\% e 0,003\%, respectivamente. Isto ocorreu porque apenas a demanda foi alterada. Como não houve deslocamento da oferta brasileira de café, o maior nível de demanda pressionou os preços de café para cima. No entanto, o efeito sobre o bem-estar das famílias foi muito pequeno, praticamente desprezível. Esses valores apresentam relevância, uma vez que indicam a possibilidade de realocação geográfica da atividade cafeeira para atender ao crescimento da demanda sem pressões altistas nos preços dos outros produtos (Tabela 3 ). 
Todavia, a importância do mercado interno só foi percebida recentemente, quando a agroindústria do café iniciou programas de melhoria na qualidade do produto destinado aos consumidores domésticos. Portanto, considerando os efeitos diretos implementados neste cenário, observa-se que o crescimento da demanda doméstica de café de qualidade deverá realocar regionalmente os fatores de produção, o que poderá influenciar os produtores nacionais no processo de produção e de processamento.

Apesar da taxa de expansão de $1,3 \%$ ao ano na demanda mundial de café, na década de 90 , o café brasileiro enfrentou algumas resistências no mercado internacional. Essas restrições vêm ocorrendo, principalmente, em razão da redução da participação do produto brasileiro na formação dos blends que são comercializados nos diversos mercados varejistas, o que explica, em parte, a maior dificuldade de crescimento da parcela de mercado do café brasileiro.

Deve-se, também, ressaltar que foram observadas mudanças nos hábitos dos consumidores, em função da estagnação ou do declínio do consumo de bebidas quentes nos mercados europeu e americano. Essas mudanças afetaram, principalmente, o consumo de café, em virtude da dificuldade de transmitir aos jovens uma imagem favorável dessa bebida, visto que já existe uma associação do seu consumo com alguma forma de malefícios à saúde causados pela cafeína. Esses fatos têm provocado maior retração no consumo de café na faixa da população jovem, principalmente de 20 a 29 anos (FARINA; ZYLBERSZTAJN, 1998).

Por outro lado, tais análises agregadas do consumo de café deixam de mostrar uma transformação importante ocorrida, na última década, nos principais mercados consumidores. Existe uma tendência de crescimento do consumo de cafés especiais nos países desenvolvidos, seja pela qualidade da bebida ou pelo seu processo de blending. Esse comportamento da demanda no mercado internacional pode ser uma vantagem para o Brasil, pois o país possui diversas regiões que produzem cafés de alta qualidade, além de ser um dos poucos países produtores que ainda dispõem de terras para incrementar a produção em condições de clima e solo favoráveis à produção de bebidas finas. 
Internamente, o consumo doméstico tem apresentado crescimento contínuo nos últimos anos, alcançando o patamar de quase 12 milhões de sacas (FARINA e ZYLBERSZTAJN, 1998). Esse cenário positivo, no entanto, foi resultante da implementação, na última década, do programa de incentivo ao consumo promovido pela Associação Brasileira da Indústria de Café - ABIC, que promoveu a auto-fiscalização do café torrado e moído. Dessa forma, o maior crescimento das vendas de café no varejo brasileiro ocorreu no segmento de preços superiores ao da cotação média, o que indica que os consumidores desses segmentos do mercado estavam dispostos a pagar um prêmio pela maior qualidade dos cafés que consumiam.

\section{Conclusões}

A importância do café brasileiro no mercado internacional levou o produtor nacional a uma certa acomodação, principalmente nos aspectos relacionados com a qualidade do produto. No momento atual, entretanto, os mercados das economias desenvolvidas sinalizam consumidores cada vez mais exigentes com a qualidade do produto. A tendência que se verifica é o crescimento do consumo de cafés especiais tanto no mercado doméstico como no externo, em especial, cafés de origem e o expresso.

Os resultados obtidos no cenário proposto indicam que a expansão da demanda, nos níveis estabelecidos, provoca efeitos positivos sobre as atividades produtivas nas regiões que apresentam maior potencial de crescimento para a produção de cafés especiais. Portanto, os ajustes na produção implicam maior racionalidade na utilização dos recursos produtivos, por meio da realocação regional da produção de café. A realocação regional da produção provocou elevação nos preços dos fatores e a conseqüente diminuição nos níveis do emprego rural e da rentabilidade do capital rural. Essas mudanças implicam em retrações nas rendas das famílias, do governo e do exterior, reduzindo o nível de bem-estar potencial.

O Brasil, mesmo nos dias atuais, ainda se destaca como importante produtor de café, já que apresenta condições de atender a 
todos os mercados, seja o de commodities, seja o de cafés mais finos. Mesmo assim, a concorrência, mediante preços e custos mais baixos, continua a ser elemento diferencial no mercado internacional, já que é fator importante na ampliação da parcela deste mercado. Porém, deve-se destacar o aumento considerável da demanda de cafés especiais, segmentos em que se observam as maiores taxas de crescimento da demanda nos últimos anos.

A realidade que se evidencia para o produtor é a necessidade de uma reestruturação na atividade produtiva a fim de explorar os nichos de mercados, pois, com a estagnação do consumo de cafés de baixa qualidade e com o aumento da concorrência entre os países produtores, a tendência é de queda no consumo do café tipo commodity. O desafio, portanto, é reverter essa situação, procurando adotar tecnologias que possibilitem a redução de custos e a manutenção do fluxo de fornecimento do café de qualidade exigida pelo mercado consumidor. A adoção de tais medidas deverá possibilitar melhor reestruturação da atividade, garantindo a continuidade de sua competitividade.

\section{Referências Bibliográficas}

AGRIANUAL. Anuário estatístico da agricultura brasileira. São Paulo: FNP Consultoria e Comércio, 1999.

AGRIANUAL. Anuário estatístico da agricultura brasileira. São Paulo: FNP Consultoria e Comércio, 2000.

ANUÁRIO ESTATÍSTICO DO BRASIL. Vários números de 1996 a 2000.

ANUÁRIO ESTATÍSTICO DO CAFÉ. Vários números de 1999-2001. AZZONI, C.R. Teoria da localização: uma análise crítica. São Paulo: Instituto de Pesquisas Econômicas, 1982. 200 p.

BRAGA, M.J. Reforma fiscal e desenvolvimento das cadeias agroindustriais brasileiras. Viçosa: UFV, 1999. 155 p. Tese (Doutorado em Economia Rural) - Universidade Federal de Viçosa, 1999.

CAPOZZA, D.R., VAN ORDER, R. A generalized model of spatial competition. American Economic Review, v. 68, n. 5, p. 896-908, 1978. 
CASTILHO, M.R. Algumas considerações sobre o uso de modelos computáveis de equilíbrio geral como instrumento de análise do setor externo brasileiro. Rio de Janeiro: Fundação Centro de Estudos do Comércio Exterior, 1994. 26 p. (Texto para Discussão, 97).

FARINA, E.M.M.Q., ZYLBERSZTAJN, D. Competitividade no agribusiness brasileiro: sistema agroindustrial do café. São Paulo: IPEA, 1998. 236 p. v. 4.

FERREIRA FILHO, J.B.S. MEGABRÁS: um modelo de equilíbrio geral computável aplicado à análise da agricultura brasileira. São Paulo: FEA/USP, 1995. 171 p. Tese (Doutorado em Economia) - Faculdade de Economia e Administração/Universidade de São Paulo, 1995. GAZETA MERCANTIL. Relatório da Gazeta Mercantil LatinoAmericana. São Paulo, 15 a 21 de setembro de 1997, p. 13-20.

NAJBERG, S., RIGOLON, F.J.Z., VIEIRA, S.P. Modelo de equilíbrio geral computável como instrumento de política econômica: uma análise de câmbio x tarifas. Rio de Janeiro: BNDES, 1995. 24 p. (Textos para discussão, 30).

NORTON, W. The relevance of Von Thünen theory to historical and evolutionary analysis of agricultural land use. Journal of Agricultural Economics, v. 30, n. 1, p. 39-47, 1979.

PIRES, M. de M. Impactos de especificidades regionais na competitividade da atividade cafeeira sobre a localização da produção e na redistribuição espacial da renda. Viçosa: UFV, 2001. 93p. Tese (Doutorado em Economia Rural) - Universidade Federal de Viçosa, 2001.

PORTER, M.E. A vantagem competitiva das nações. Rio de Janeiro: Campus, 1993. 897 p.

TOMEK, W.G., ROBINSON, K.L. Agricultural product prices. 2.ed. Ithaca, New York: Cornell University, 1991. Cap. 8, p. 139-156.

WRIGHT, C.L. Método econométrico: algumas reflexões sobre a obra pioneira de Von Thünen. Brasília: UnB/GEIPOT, 1982. 21 p. (Texto para Discussão, 93). 